\title{
A nobreza em movimento
}

La nobleza en movimiento

The Nobility in movement

La noblesse en mouvement

Júnia Ferreira Furtado ${ }^{[1]}$

RAMINELLI, Ronald. Nobrezas do novo mundo: Brasil e ultramar hispânico, séculos XVII e XVIII. Rio de Janeiro: Editora FGV, 2015. 200p.

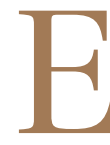

m 1982, Desclassificados do Ouro, de Laura de Mello e Souza, renovou os estudos sobre a colônia ao trazer, para a cena histórica, "a pobreza mineira no século XVIII", com seus marginalizados sociais, que surgiam na esteira do processo de centralização do estado moderno (Souza, 1982). Se a década de 1980 se caracterizou, no Brasil, pelo alargamento do campo histórico de análise, para incluir esses grupos "de baixo", as camadas populares, ${ }^{2}$ o século XXI, na vertente oposta, assistiu ao renascimento do interesse pelo estudo das elites, ${ }^{3}$ nesse caso centrando-se no estudo da nobreza que emerge no contexto do período colonial. Esse movimento nasceu conjuntamente com um diálogo mais estreito que os historiadores brasileiros passaram a encetar com a historiografia portuguesa, destacando-se, nesta última, os estudos de António Manuel Hespanha (1997;2007), Nuno Gonçalo Monteiro (1993;2003), Mafalda Soares da Cunha (1990;2000), Diogo Ramada Curto (1988), Fernanda Olival (2001) e Pedro Cardim (1998), ${ }_{,}^{4}$ entre outros, que, então,se debruçavam sobre as elites, a aristocracia e a nobreza portuguesas,em um contexto de Antigo Regime.

Arriscaria apontar que, nessa vertente, no Brasil, o despertar pelo tema das formas, dos critérios e dos dilemas que as elites do Novo Mundo encontraram para se inserir no seio da nobreza lusitana foi inaugurado com o livro de Evaldo Cabral de Mello, O Nome e o Sangue (1989), ${ }^{5}$ no qual o historiador pernambucano "conta a história de uma manipulação genealógica destinada a esconder, no Pernambuco da segunda metade do século XVII e ao longo do século XVIII, o costado sefardita de uma importante família local" (Mello, 1989, p.11). Esse

Resenha recebida em 16 de outubro de 2015 e aprovada para publicação em 30 de outubro de 2015.

[1]Professora Titular do Departamento de História da Universidade Federal de Minas Gerais - Belo Horizonte (MG) - Brasil.

E-mail: juniaf@fafich.ufmg.br

${ }^{2}$ No que diz respeito a essa renovação, no panorama internacional, cabe destacar, entre os inúmeros estudos que exerceram impacto no Brasil, o de Hill (1987).

${ }^{3}$ Entre os trabalhos precursores dessa vertente, destaco Burke (1991) e Goff (1991).

${ }^{4}$ Ver também Cardim; Monteiro e Cunha (2005).

${ }^{5}$ Análise sobre o livro pode ser vista em Furtado (2008, p.57-85) 
estudo se centra "num momento específico da vida de Filipe Pais Barreto, descendente de importante família da oligarquia açucareira de Pernambuco, que, em 1700, recebeu do rei de Portugal a honra de ostentar o título de cavaleiro da Ordem de Cristo" e que esperava, com tal mercê, assegurar "doravante o destino que lhe era reservado pelo nascimento: 'viver na nobreza, servindo-se de bestas e criados', como era o costume no nordeste açucareiro entre a elite da terra - os senhores de engenho e seus descendentes", imitando a nobreza reinol (Furtado, 2008, p.58-61). A partir desse caso, o autor analisa "o conceito de nobreza, a hierarquia e os privilégios de sangue [que] faziam com que a linhagem e a genealogia ocupassem papéis importantes na manutenção e na transmissão do status quo" (Mello, 1989, p.67).

\section{O século XXI assistiu ao renascimento do interesse pelo estudo das elites, nesse caso centrando-se no estudo da nobreza que emerge no contexto do período colonial}

Entre esse livro de Cabral de Mello, hoje um clássico, e o recente de Ronald Raminelli, passaram-se pouco mais de 25 anos. Esse último estudo revela que foi tempo mais do que suficiente para aprofundar e refinaras análises sobre o que configurava ser nobre no Brasil colonial. A conjugação entre fontes (muitas inéditas ou pouco ou nada trabalhadas) e a extensa bibliografia sobre a nobreza no espaço ibérico, isto é, Portugal, Espanha e América luso-hispânica, de que este autor pôde se beneficiar permitem a produção de um estudo instigante sobre o tema, propondo,em muitos aspectos, interpretações inéditas e inovadoras, que revelam um pesquisador maduro e afinado com as novas metodologias do trabalho histórico.

Em primeiro lugar, é imperativo voltar a esse ponto para chamara atenção para a massiva variedade de livros, capítulos de livros e artigos com que Raminelli dialoga para embasar muitas das assertivas que faz ou que, por vezes, são alvo de sua crítica. Ademais, essa bibliografia torna-se essencial para que se possa estabelecer uma comparação com o mundo espanhol e, dessa maneira, aproximar ou identificar diferenças entre o que acontece nos diversos espaços dominados pelas duas coroas ibéricas, no além e no aquém mar. Essa se constitui uma das grandes virtudes e inovações desse estudo, o que requer erudição e contínua atualização bibliográfica, permitindo que a análise não se atenha apenas ao mundo luso-brasileiro, como acontece, de modo mais recorrente, com a maioria dos estudos.

O pleno domínio e a ampla capacidade de estabelecer um diálogo crítico com a bibliografia atingem o ponto máximo no último capítulo, "Cores, raças e qualidades", no qual são abordadas as questões do racismo e do preconceito racial, tornando-se esse texto, doravante, de leitura incontornável para os futuros estudos sobre esses temas. Nesse caso, não se trata apenas da historiografia 
luso-espanhola, mas também de autores franceses, italianos, ingleses, alemães e norte-americanos, que abordam essa questão para diversos espaços no contexto da expansão colonial europeia moderna.

No entanto, a armadilha nesse tipo de opção metodológica é que, como esse diálogo não se estrutura também a partir de pesquisas de fontes primárias, que não puderam ser realizadas para o lado espanhol, em razão da tarefa hercúlea que tal procedimento exigiria, muitas vezes, o leitor não consegue estabelecer uma relação crítica com a bibliografia hispânica selecionada. Um exemplo limite dessa dificuldade aparece quando o autor aponta, em nota (Raminelli, 2015, p.112), que um artigo de Langue (1999) contraria a afirmação de Lira Montt (1981) de que "na Espanha os nobres titulados gozavam de senhorios territoriais e vassalos perpétuos, benefícios inexistentes nas Índias". Em que se baseia essa discordância? Novas pesquisas documentais? Quais? Que elementos permitem que eu, leitor,me posicione a favor de uma ou de outra interpretação e adote a mesma posição de Raminelli em favor da interpretação de Lira Montt?

Ainda que o centro da análise, como se explicita no subtítulo do livro, situe-se entre os séculos XVII e XVIII, o autor também aborda, quando se faz necessário, o XVI e o alvorecer do XIX, de modo a apreender as transformações ocorridas, muitas delas perceptíveis apenas na longa duração. O objetivo é compreender o que se define como nobreza, como se constitui, se estrutura e se identifica; os mecanismos de acesso, comparando tanto o espaço reinol como o americano, no que diz respeito aos impérios português e o espanhol, este tomado como base de comparação.

Nesse aspecto, o conceito adotado sobre o que é ser nobre é o institucional, que divide a nobreza entre a de linhagem e a de serviço, essa última alcançada por concessão régia. Nas sociedades de Antigo Regime, como era o caso de Portugal na era moderna, o lugar que cada indivíduo ocupava se baseava no nascimento. Era um mundo no qual a ordem social hierarquizada distinguia uns em detrimento de outros, buscando demarcar e separar, nitidamente, os estratos mais altos - aqueles a quem se conferia nobreza - dos mais baixos ou vis - os plebeus. Ser nobre, portanto, era estar entre os principais, a diferença constituindo o cerne desse mundo.

No capítulo um, o que se busca compreender é o que se configura como nobreza, investigando as normas legais exaradas para tanto. Por outro lado, o que se coloca como o grande tema de investigação, questão que perpassa os capítulos dois a cinco, é a possibilidade de ascensão de indivíduos cuja nobreza é alcançada não pelo nascimento, mas pela riqueza ou pelos préstimos/serviços realizados em prol do império e quem atinge, de maneira adquirida, tais patamares nas duas regiões - Ibéria e América hispânica. É essa nobreza de mérito - concedida pelo rei aos súditos da América portuguesa - e, na sua contramão, a quem tal honra não era concedida, ainda que seu pretendente preenchesse 
os critérios normativos para alcançá-la, que interessam, de modo central, ao autor. A ampla pesquisa de fontes busca encontrar as respostas para essas questões e para os paradoxos resultantes dessas possibilidades ou impossibilidades de alcançar nobreza em terras do além-mar. Quem se beneficiava desse mecanismo e, no sentido oposto, quem era excluído? Como a norma respondeu a essa demanda de ascensão nobiliárquica de estratos não nobres? Para responder a essas e a outras tantas perguntas, Raminelli, de maneira inovadora, associa o interesse que a historiografia devotou, tanto aos marginalizados quanto às elites (sem, no entanto, utilizar esse termo como conceito), ${ }^{6}$ porque, afinal, grande parte dos pretendentes era formada por negros, índios e mulatos, ou seja, constituíam o outro em relação à elite branca europeia.

\section{A ampla pesquisa de fontes busca encontrar as respostas para essas questões e para os paradoxos resultantes dessas possibilidades ou impossibilidades de alcançar nobreza em terras do além-mar}

Para compreender o processo ou as dificuldades de nobilitação, mas recusando o conceito de nobreza da terra muito em voga em trabalhos mais recentes (Fragoso et al, 2001; Fragoso, 2003, p.11-36), o livro se debruça sobre os diferentes mecanismos utilizados por esses estratos em ascensão, como os serviços camarários, realizados pelos homens bons, (capítulo dois), a riqueza e o mérito (capítulo três) e as guerras brasílicas, nas quais se alistaram índios e negros (capítulos quatro e cinco).

A parte mais instigante se localiza exatamente no capítulo quatro, quando Raminelli examina as tentativas de nobilitação da nobreza indígena, as maneiras como eles "se inseriam na hierarquia social do Antigo Regime" e, finalmente, questiona "se as insígnias das Ordens Militares portuguesas teriam o mesmo significado para portugueses e índios" (Raminelli, 2015, p.135). Nessa parte, o autor manipula, com maestria, as fontes primárias - os pedidos de mercês indígenas protocolados em troca dos serviços militares realizados nas guerras contra os invasores estrangeiros, holandeses e franceses - para o Brasil. Ainda que afirme (Raminelli, 2015, p.136) que "para [esses] questionamentos ainda não obtive dados conclusivos", o autor propõe uma conclusão totalmente inovadora. Segundo ele,como "tradicionalmente entre os tupis, as lideranças eram efêmeras, [e] raramente o poder de comando passava ao filho", o recurso aos mecanismos de nobilitação dos portugueses foi "tática indispensável para

${ }^{6}$ Nesse sentido, como alerta, no Prefácio, Ronaldo Vainfas, "o livro se afasta da tendência da historiografia brasileira, mais ou menos recente, de 'sociologizar' o conceito de nobreza, assimilando-o ao conceito de elite". In: Raminelli (2015, p.11). 
perpetuar a liderança, o controle político de [uma] família [ao longo de diversas gerações] sobre as comunidades indígenas" (Raminelli, 2015, p.172).

Tal parece não ter ocorrido na América espanhola, onde, de um lado, à coroa nunca interessou conceder às lideranças indígenas tais títulos (Raminelli, 2015, p.18), visto que o que se buscava era, efetivamente, solapar-lhes o poder e, de outro, aos líderes nativos não era necessário recorrer às formas de nobilitação europeia para conservarem seu poder sobre suas comunidades, pois esse já estava consolidado no seio das estruturas políticas pré-hispânicas. Ora, para mim, essa distinção mereceria, por si só, um livro em separado, no qual o método comparativo buscasse, a partir de pesquisa de fontes também para a área espanhola, confirmar, ou não, as diferenças entre as estratégias indígenas no que concerne à nobilitação das lideranças nativas e as reações a elas por parte das duas coroas hispânicas.

Ao trazer para a cena as populações negras, índias e mestiças, tornou-se imperativo para o autor discutir os impasses e os paradoxos decorrentes do fato de que populações com outro sangue, modo de vida, moral e religião buscassem nobreza, ameaçando os critérios pelos quais os nobres reinóis, de ascendência branca, europeia e cristã, até então se constituíam e se distinguiam dos estratos sociais inferiores. No capítulo seis, que fecha o livro, Raminelli reflete sobre a viabilidade, ou não, do uso dos conceitos de raça e de racismo para analisar os mecanismos para a exclusão de parte das populações do novo mundo que buscava lugar no seio da nobreza imperial. $\mathrm{O}$ autor não cai na armadilha do uso a-histórico desses dois conceitos, visto que "são baseados no determinismo biológico oitocentista", ou na sua recusa total, já que "não são adequados para pensar as relações sociais entre os séculos XVII e XVIII" (Raminelli, 2015, p.209). Nesse sentido,defende que, se o critério de raça, tal como seria empregado mais tarde, não era o acionado para impedir que essas populações (incluindo os cristãos-novos) tivessem acesso à nobreza, o conceito de racismo seria operacionalmente útil para compreender esses processos de exclusão.

Para tanto, discutindo com rara perspicácia com a historiografia mais recente, inclusive a brasileira, ${ }^{7}$ Raminelli resgata os termos que emergem da documentação de época, como o sangue, a qualidade, a cor e a condição (nesse caso a escrava), por meio dos quais se constituíam os impedimentos para se enobrecer. Dessa maneira, transforma a linguagem coeva em conceitos, o que lhe permite historicizar os mecanismos sociais de exclusão das populações nativas (índios, negros e mulatos) do Novo Mundo. Tal procedimento é próprio de pesquisador da melhor estirpe, afinado com os métodos mais recentes de análise historiográfica.

"Júnia Ferreira Furtado é bolsista 1A do CNPq e do Programa Pesquisador Mineiro da FAPEMIG."

${ }^{7}$ Como Lara (2007); Viana (2007); Krause (2012). Uma ausência que merece destaque é Rodrigues (2011). 


\section{Referências bibliográficas}

BURKE, Peter. Veneza e Amsterdã, um estudo das elites do século XVII. São Paulo: Brasiliense, 1991. CARDIM, Pedro. Cortes e cultura política no Portugal do Antigo Regime. Lisboa: Cosmos, 1998; CARDIM, Pedro; MONTEIRO, Nuno. G. e CUNHA, Mafalda S. Optima Pars. Elites Ibero-Americanas do Antigo Regime. Lisboa: Imprensa de Ciências Sociais, 2005.

CUNHA, Mafalda Soares da. A Casa de Bragança (1560-1640). Práticas Senhoriais e Redes Clientelares. Lisboa: Editorial Estampa, 2000.

CUNHA, Mafalda Soares da. Linhagem, parentesco e poder. A Casa de Bragança (1384-1483). Lisboa: Fundação da Casa de Bragança, 1990.

CURTO, Diogo Ramada. O discurso político em Portugal (1600-1650). Lisboa: Projecto Universidade Aberta, 1988.

FRAGOSO, João et al. (orgs.) O Antigo Regime nos trópicos: a dinâmica imperial portuguesa (séculos XVI-XVIII). Rio de Janeiro: Civilização Brasileira, 2001.

FRAGOSO, João. A nobreza vive em bandos: a economia política das melhores famílias da terra do Rio de Janeiro, século XVIII. Tempo, Niterói, v.8, n.15, p.11-36, 2003;

FURTADO, Júnia Ferreira.O cristão e o converso ou uma parábola genealógica no sertão de Pernambuco. In: SCHWARTZ, Lilia Moritz. (org.) Leituras críticas sobreEvaldo Cabral de Mello. São Paulo/Belo Horizonte: Ed. Fundação Perseu Abramo/ Ed.UFMG, 2008.

GOFF, Jacques Le. Mercadores e banqueiros da Idade Média. São Paulo: Martins Fontes, 1991. HESPANHA, António Manuel (org.). História de Portugal - volume 4. O Antigo Regime. Lisboa: Estampa, 1997 (direção de José Matoso).

HESPANHA, Antônio Manuel. A mobilidade social na sociedade de Antigo Regime. Tempo, v.1, n.2, p.121-143, 2007.

HILL, Christopher. O mundo de ponta-cabeça: ideias radicais durante a Revolução Inglesa de 1640. São Paulo. Companhia das Letras,1987.

KRAUSE, Thiago. Em busca da honra. São Paulo: Annblume, 2012.

LARA, Sílvia H. Fragmentos setecentistas. São Paulo: Companhia das Letras, 2007.

MELLO, Evaldo Cabral de. O nome e o sangue: uma fraude genealógica no Pernambuco colonial. São Paulo: Companhia das Letras, 1989.

MONTEIRO, Nuno Gonçalo. Elites e poder: entre o Antigo Regime e o Liberalismo. Lisboa: Imprensa de Ciências Sociais, 2003.

MONTEIRO, Nuno Gonçalo. O crepúsculo dos grandes. A casa e o patrimônio da aristocracia em Portugal (1750-1832). Lisboa: Temas Portugueses, 2003.

MONTEIRO, Nuno Gonçalo. Poder senhorial, estatuto nobiliárquico e aristocracia. In: HESPANHA, António Manuel. (org.) História de Portugal - volume 4. O Antigo Regime. Lisboa: Editorial Estampa, 1993, p.333-380.

OLIVAL, Fernanda. As Ordens Militares e o Estado Moderno: honra, mercê e venalidade em Portugal (1641-1789). Lisboa: ESTRAR, 2001.

RODRIGUES, Aldair Carlos. Limpos de sangue: familiares do Santo Ofício, Inquisição e sociedade em Minas Gerais. São Paulo: Alameda, 2011.

SOUZA, Laura de Mello e. Desclassificados do ouro: a pobreza mineira no século XVIII. Rio de Janeiro: Graal, 1982.

VAINFAS, Ronaldo. Prefácio. In: RAMINELLI, Ronald. Nobrezas do novo mundo. Rio de Janeiro: FGV, 2015.

VIANA, Larissa. O idioma da mestiçagem. Campinas: Editora Unicamp, 2007. 